Boise State University ScholarWorks

Civil Engineering Faculty Publications and

Presentations

Department of Civil Engineering

$1-1-2010$

\title{
Estimation of the Water Balance Using Observed Soil Water in the Nebraska Sandhills
}

\author{
Venkataramana Sridhar \\ Boise State University \\ K. G. Hubbard \\ University of Nebraska-Lincoln
}




\title{
Estimation of the Water Balance Using Observed Soil Water in the Nebraska Sandhills
}

\author{
Venkataramana Sridhar \\ Boise State University \\ K. G. Hubbard \\ University of Nebraska-Lincoln
}

\begin{abstract}
Analyzing the dynamic hydrologic conditions of the Sandhills is critical for water and range management, sustainability of the Sandhills ecosystem as well as for dune stability. There are complex models available to quantify both surface and subsurface hydrological processes. However, we present in this study an application of a relatively simple model to arrive at best estimates of the water balance components. Using the Thornthwaite-Mather (TM) model, water balance components were estimated for 4 Automated Weather Data Network (AWDN) weather monitoring stations. Estimated averages of the water balance components suggested that mean annual precipitation of these four sites was only about $420 \mathrm{~mm}$ but water loss through plant evapotranspiration (ET) was $861 \mathrm{~mm}$, with PET of about $1214 \mathrm{~mm}$. Our investigation shows that there was surplus of water between December and March and a deficit occurs at the start of the growing season in May and extends through senescence in September-October. This study also suggests that the High Plains aquifer possibly met the plant water requirement during this deficit period as well as during the soil water extraction period, from May through September.
\end{abstract}

Key words: water balance, soil water, Sandhills, Nebraska

\section{Introduction}

Excessive use of water and depleting water resources over many regions in the world have caused demand to exceed supply. The future holds uncertain climate variability and climate change, thus unsustainable competition for available water is possible. Limited water resources may in fact lead to societal conflict. It is critical to identify these regions and develop a reasonable modeling approach to characterize the hydrologic conditions over a period of time. The Nebraska Sandhills is one such region where water is abundantly present (Bleed and Flowerday, 1998) both at the surface level (such as lakes and wetlands) and the sub-surface levels (ground water). However, wise water and land management practices can play a vital role in the sustenance of this vast dune landscape which is known as a "desert in disguise". Poor management could result in the loss of grass cover over the dune tops and interdunal valleys thereby altering the water budget and soil water conditions. Alteration of the water budget can result in exposed soils and increase the chances for wind-blown erosion and dune migration to the neighboring areas. Presumably the magnitude and direction of sand transport will depend on the wind speed and direction. Destabilization and movement of these ubiquitous sand dunes would adversely impact on the cattle industry thereby causing substantial loss of revenues for the ranchers of this region.

Numerous studies have addressed the complex dynamics of the Sandhills and converged on one finding that there is a strong interplay between surface and groundwater systems (e.g., Gosselin et al., 1999; Chen and Chen, 2004; Gosselin et al., 2006). However, thorough understanding of the water balance dynamics in this region is still limited due to the associated challenges, especially in terms of dynamic coupling of the surface and ground water resources. One limitation to researchers, in this regard, is the lack of high-resolution data to perform any physically-based, distributed hydrological modeling. The recent focus on linking soil water and evapotranspiration (ET) with the atmospheric processes demonstrates the importance of the land-atmosphere exchange processes (e.g., Mahmood and Hubbard, 2003; Delworth and Manabe, 1989; Delworth and Manabe, 1988; Iturbe, 2000). Sridhar et al., (2002) modeled the surface energy balance components including net radiation, latent, sensible and ground heat fluxes for some selected sites in Oklahoma using the state-of-the-art weather network data (McPherson et al., 2007) where daytime heating during summertime and the resulting ET is considered to have a significant effect on short-term weather and long-term water status. The lack of data is a major constraint in implementing a similar modeling approach in the Sandhills. Thus, it becomes crucial to implement a relatively simple approach to understand the water balance characteristics, particularly ET, with available data and methodology. The Thornthwaite-Mather (TM) 
model is widely used in various regions to compute water balance across various scales, such as watershed (Singh et al., 2004), regional (Hebert and Jack, 1998) and continental (Feddema, 1998) scales and is proven to provide reasonable estimates on a monthly or seasonal basis for water balance components of a region. The TM model computes the water balance using an accounting procedure that partitions the water among various components of the hydrologic budget. This model uses monthly temperature and precipitation as inputs and calculates monthly potential and actual evapotranspiration, soil water storage, snow storage, surplus, and runoff as outputs. There are complex models available to quantify surface-ground water interaction, but these require data and information not readily available in the Sandhills. We present in this study an application of a relatively simple model to arrive at practical estimates of the water balance components.

The objective of this study is to adopt the TM model for estimating the water balance components for 4 Automated Weather Data Network (AWDN) weather monitoring stations and to characterize the water status over the Sandhills region. As opposed to the general method of using monthly temperature-based Potential ET (PET) in the TM model, we estimated Penman-based PET using daily data from the AWDN weather data (Hubbard et al. 1983) in the TM model to compute the water budget. The urgent need for understanding the water balance dynamics in the Sandhills not only motivates this research but also provides a preliminary estimate of actual $\mathrm{ET}\left(\mathrm{ET}_{\text {act }}\right)$, runoff, water deficit and surplus status by combining surface and sub-surface features that can be attributed to this region. Though this model has been applied on a grid by grid basis in other studies (Singh et al. (2004), our approach in this investigation is to first apply the TM model over selected sites using individual weather station data and then to estimate regional averages in comprehending the regional water balance.

\section{The Sandhills}

The Sandhills of Nebraska is the largest sand dune area in the Western Hemisphere covering about $58,000 \mathrm{~km}^{2}$. This dune landscape is stable at present and supports the economic endeavors of the population in the region. The dunes are typically $122 \mathrm{~m}$ high and $32 \mathrm{~km}$ long. Geologically these dunes were mobile until recently. The optically stimulated luminescence (OSL) dating records showed that the destabilization and movement occurred about 900 years ago (Loope and Swinehart, 2000). If the dunes become active again, the devastation on the cattle enterprise, wildlife, and local community economics could be enormous. Beneath these grass-covered sand dunes, one of the largest groundwater aquifers known as the High Plains (or Ogallala) aquifer exists (Bleed and Flowerday, 1998). This aquifer is constantly recharged especially between September and April. Because of the undulating topography of the Sandhills, the hydrological characteristics show a remarkable variability over these areas. In other words, the dry-sand dunes of this region are interspersed with shallow lakes and wetlands in the interdunal valleys and these water bodies are primarily fed by the aquifer (Gosselin et al., 2006). Thus, the abundance of water beneath the Sandhills not only helps maintain the grass cover over the dunes but also feeds the lakes and wetlands apart from providing a constant supply of discharge into the streams in the region (Chen and Chen, 2004).

Spatial variability in precipitation and micro-climatic conditions are quite evident with the eastern Sandhills region receiving an annual average rainfall of $58 \mathrm{~cm}$, the western edge receiving only an average of $43 \mathrm{~cm}$. This variability in precipitation is attributed mainly to the barrier effect of the Rocky mountain range and the remoteness from the Gulf of Mexico (Bleed and Flowerday, 1998). Annual average temperature of this region is around $9{ }^{\circ} \mathrm{C}$. However, the trend in average maximum and minimum temperatures shows the eastern region with lower temperatures and the west with higher temperatures and the difference in magnitude is about $1-2{ }^{\circ} \mathrm{C}$. The topography of the region is also partly responsible for the varied wind and snowfall pattern observed during the seasons.

In general, the predominant soil type of the Sandhills is sand. A minimal variation in sandy soils exits between dune tops and interdunal valleys. Highly permeable coarse sand is present over the dune top that supports deep rooted warm season grasses which can extract infiltrated water deep beneath the dunes. A fine textured sandy soil with relatively high water holding capacity is available in the interdunal valleys and this supports the shallow-rooted cool-season grass. About $4 \%$ of the area in the Sandhills is irrigated using groundwater, however, the erodible nature of the soil prohibits wide-spread adoption of irrigation techniques such as center-pivot systems. This landscape also provides an opportunity for two of the man-made forests to thrive successfully.

\section{Weather Network And Data}

The High Plains Regional Climate Center (HPRCC), located at the University of Nebraska-Lincoln, serves as a hub and repository for data from the High Plains region called the Regional Automated Weather Data Network (AWDN). This AWDN collects a suite of hydrological, meteorological and agricultural variables in support of 
region-wide soil water and drought assessment research and also maintains seamless connections between HPRCC and other climate centers to disseminate climate data. There are 181 automated weather stations in a 10-state region and 60 of these stations located in Nebraska also measure near-surface weather variables and soil water variables. We used data for this investigation from four sites that fall within the Sandhills region, although one of them, O'Neil, is located along the eastern boundary of the Sandhills. The location map of the Sandhills Region and the sites are shown in Fig. 1. The AWDN stations used in this study are spread across the entire Sandhills region evenly; they are: Ainsworth (AIN), Arapahoe (ARA), Gudmundsens (GUD), and O'Neil (ONE). Both AIN, ARA are located in native, upland grassland, GUD is located near a hay meadow and ONE is located in pastures dominated by non-native grasses on the northeastern edge of the Sandhills. Figure 2 (a) shows the elevation derived from the digital elevation model (DEM) at $30 \mathrm{~m}$ resolution. The terrain presents a relatively homogenous topography. Figure 2(b) illustrates the vegetation homogeneity using Landsat $30 \mathrm{~m}$ data for the Sandhills region.

The soil water profiles show distinct patterns representing the regional variability in the Sandhills. Monthly totals of precipitation from these four sites for 5 years between 1999 and 2003 were computed for use in the calculation of monthly water balance from the TM model that is described in a subsequent section. Also, daily Penman-based PET was computed and aggregated to monthly totals for use in the TM water balance analysis.

\section{Method}

Using the weather data available from 4 AWDN stations mentioned above, PET was computed at a daily time step using the Penman combination equation. The basic variables needed to compute Penman PET are solar radiation, temperature, humidity and wind speed. Note that the approach to PET in the subsequent water balance computation was different from the original TM approach. In this study the daily PET estimates were summed to get the monthly totals and subsequently used to estimate the routine monthly water balance components for each site. Furthermore, PET estimates are more physically representative as they are based on daily environmental variables that are dynamic in this region. Therefore, the monthly totals of PET from this investigation are quite accurate as opposed to those used in the original TM model wherein the model computes monthly potential ET using mean monthly temperature and annual heat index. It is possible that precipitation can affect ET by altering the soil water conditions at a shorter time scale, however, the excess water available beyond the root zone depth is accommodated in ET through PET. Also, we used observed soil water data for each site to compute the storage term in the TM model for the root zone depth of the soil and substituted directly in the computation. Therefore, this method also varies from the original TM model wherein accumulated potential water loss and available water capacity were needed to compute the storage term. The procedures described below to compute storage, actual evapotranspiration $\left(\mathrm{ET}_{\text {act }}\right)$, deficit and surplus are similar to the TM approach and Singh et al. (2004) describes the step-by-step method of computing various water balance components. The fundamental water balance equation is:

$$
\frac{\partial S}{\partial t}=P+I-E T-R-D
$$

where $\mathrm{S}$ is soil water in the root zone $(\mathrm{mm}), \mathrm{t}$ is time (day), $\mathrm{P}$ is precipitation $(\mathrm{mm} /$ day), $\mathrm{I}$ is irrigation $(\mathrm{mm} /$ day), ET is actual evapotranspiration ( $\mathrm{mm} /$ day), $R$ is runoff ( $\mathrm{mm} /$ day) and $D$ is drainage below the root zone $(\mathrm{mm} /$ day).

Using the computed PET, the difference between precipitation (P) and PET (P- PET) was computed to estimate excess (+) or deficit (-) of water. We assumed that the rooting zone reached a depth of $120 \mathrm{~cm}$ (Sridhar et al., 2006). Thus, the storage in the root zone layer is based on the observed soil water in the soil column of $120 \mathrm{~cm}$ from the surface. The study sites are equipped with Vitel soil water probes (Stevens Water Monitoring Systems, Inc) to monitor the volumetric soil water.

Using these soil water measurements, change in soil water storage $(\Delta S)$ was computed by subtracting the previous (i-1) month's storage from the current (i) month's storage.

$$
\Delta S=S_{i}-S_{i-1}
$$


The actual evapotranspiration, $\mathrm{ET}_{\text {act }}$ was computed for each month using the change in storage in soil water and precipitation.

$$
\begin{array}{ll}
E T_{a c t}=P-\Delta S, & \text { if } \Delta \mathrm{S} \leq 0 \\
E T_{a c t}=P+\Delta S & \text { if } \Delta \mathrm{S}>0 \\
E T a c t=P E T, & \text { if } \Delta \mathrm{S}>0
\end{array}
$$

If the change in storage is positive, equation 4 (a) and (b) is applied and the least of the two is considered for computing actual ET. If the change in storage is positive, it indicates that additional soil water beyond the soil column storage is either available for ET or drainage. When soil water storage beyond the root zone can be adequate, it is reasonable to assume that plant transpiration can occur at the potential rate. Generally, actual ET is related to soil water conditions. However, soil water in the study area is not constrained as noticed from the observed soil water data. When the storage exceeds the capacity of the soil column, both lateral (runoff) and vertical (drainage) discharge is accounted for in the computation as described in the following equations. When the environmental demand for water use (PET) is higher than the amount of water evaporated, there is a deficit evapotranspiration. A deficit occurs when PET exceeds precipitation (P):

$$
\text { Deficit }=P E T-E T_{\text {act }}
$$

Fig. 3 shows the monthly observed soil water trend for the period between 1998 and 2006 which was subsequently used to estimate mean annual soil water storage in the root zone layer. As can be seen from Fig. 4, ARA showed a significant drop in soil water between April- May while the other sites showed either the same amount or increased soil water compared to the preceding month. It is possible that the unusually dry season in 1999-2000 can be attributed to this drastic decrease in soil water at the start of the growing season. Predictions by the hydrology model for this corresponding period for all the sites showed a similar trend as shown in Figure 4. When soil water in the soil column is below the mean annual storage, there is no surplus water. However, when the soil water storage is equal to or above its annual average, the TM model considers it as surplus which can be computed using the following equation as

$$
\text { Surplus }=P-(\text { ETact }-\Delta S)
$$

The surplus therefore, becomes runoff and there is a time lag between precipitation and runoff (Singh et al., 2004). Due to highly permeable sandy soils in the study area, the runoff is normally episodic in nature. Based on the assumptions provided by Singh et al., 2004, wherein 50\% of surplus water that is available for runoff can be attributed to actual runoff, we computed runoff for each month. This can occur typically after a high-intensity rain for a short time. Results of the monthly analysis of the water balance are shown in Table 1 for each site and discussed in the Results and Discussion section. We also compared our results using the Robinson-Hubbard Hydrology model to quantify the vertical flux at the bottom of the root zone for the study sites (Sridhar et al., 2006) and the RMSE and Pearson correlation coefficient computed for the RH model results are presented (Table 2).

\section{Results and Discussion}

Table 1 show the site-wise 5-year average observed monthly totals of precipitation (P) and computed PET. Additional water balance components derived from these two variables using the TM model were actual evapotranspiration ( $\left(\mathrm{ET}_{\mathrm{act}}\right)$, deficit, surplus and available runoff. In general, the Sandhills region received annual precipitation of about $420 \mathrm{~mm}$. AIN and ONE received the highest annual $P$ of about $470 \mathrm{~mm}$ while ARA and GUD received about $370 \mathrm{~mm}$. As seen from the monthly $\mathrm{P}$ values, the region clearly received at least 90 percent or more of its annual P between March and October, with their peak values in May-July of about $70 \mathrm{~mm} / \mathrm{month}$. Computed PET, which is the uppermost value for any given site in the absence of soil control on the ET process, showed a drastic increase between April-July, followed by a sharp decline between September and December. PET was minimal between December and February ranging between 30 and $40 \mathrm{~mm}$ and a maximum PET of about $213 \mathrm{~mm}$ occurred in July. Out of 4 sites, AIN exhibited the highest annual total PET of $1476 \mathrm{~mm}$. As high precipitation events start near the end of the early growing season and continue for the reminder of the growing season, the grasslands ecosystem showed vibrant growth resulting in increased $\mathrm{ET}_{\text {act }}$ values between April-May. As in Fig 5, these results matched with the hydroclimatology of the Robinson-Hubbard hydrology model for the study sites 
between 1999 and 2003 (Sridhar et al., 2006). For instance, the wet years showing higher soil water recharge and dry summers showing no recharge matched with our seasonal pattern of the early Spring recharge and Summer/Fall deficit (Fig. 6).

Due to relatively high soil water content in the soils resulting from snowmelt combined with the on-set of spring precipitation events, high soil water storage values were observed between April-May and the decline in soil water storage started in May-June. In general, change in soil water storage on a monthly scale shifted from positive to negative in the growing season, which served as an indicator for the soil column to change from surplus to deficit. From Fig. 3 and Fig. 5, observed soil water in the root zone or the storage term in the TM model was generally high in the early Spring and peaked in May. Except for AIN, all other sites have sandy soils and therefore the soil water retention or storage was less when compared to AIN. The soil type at AIN is silty and as a result, higher root zone soil water storage could be observed with an annual average of $244 \mathrm{~mm} / \mathrm{month}$ while for GUD, ONE and ARA, observed soil water storage values were about 165,120 and $100 \mathrm{~mm} /$ month, respectively. Given the higher demand of water by the plants in the early and mid-growing season, higher utilization of soil water during this time was reasonable, as reflected in high values of $\mathrm{ET}_{\text {act }}$ for the same period. From the annual totals of $\mathrm{ET}_{\text {act }}$, there were distinct variations among the study sites, with values ranging between 700-1000 mm. AIN and ARA exhibited a maximum value of about 1018 and $911 \mathrm{~mm}$, respectively and ONE showed the minimum of $716 \mathrm{~mm}$.

The surplus amount of water was available approximately between Jan and May and the dramatic increase in $\mathrm{ET}_{\text {act }}$ starting from May resulted in deficit of available water for plants between April through September. We computed the surplus component of the water budget using equation 6 by adding the storage with $\mathrm{ET}_{\text {act }}$ and then subtracting from precipitation. This obviously resulted in surplus for AIN in May when storage was the highest $(347.41 \mathrm{~mm})$ in the year. Because of the spring snowmelt and Spring-Summer precipitation events due to moisture transport from Gulf of Mexico to the central plains where Nebraska is located, we normally see high soil water content in early Spring. Furthermore, it is obvious from this monthly water budget calculation that the deficit due to excessive ET will show up in the subsequent month calculation as can be seen from Table 1. There was no surplus as the soil water storage declined with higher ET and less precipitation in June. Annual total surplus among the four sites ranged between 136 and $345 \mathrm{~mm}$. ARA had the highest surplus and ONE had the least. Winter precipitation was insignificant at AIN which naturally reduced the available water for ET and soil water storage between Nov and February. This is true for the other three sites as well and in the entire Sandhills. The surplus period was normally in the early Spring between March and May when numerous ephemeral lakes sprung up in this region. On the contrary, the deficit was clearly seen for all sites with annual values ranging from 280 at ARA to $457 \mathrm{~mm}$ at AIN. Despite high precipitation and high soil water storage values, both PET and $\mathrm{ET}_{\text {act }}$ drastically depleted the soil water at AIN and therefore caused significant deficit. Generally, estimated annual hydrologic budget for the study cites using RH model agreed well with our current estimates. In this study, runoff includes both surface and sub-surface flow and it compares well with the hydrology model predicted runoff that includes drainage that varied between $130 \mathrm{~mm}$ to 300 $\mathrm{mm}$ and this agrees with our estimates of runoff in the current methodology. Basically, the RH model does not account for groundwater exchanges and excess water was drained into the aquifer. Available water in the root zone was used by the plants and ET from the grasslands in the Sandhills was less as compared to the actual conditions. However, with the TM approach since the water balance was reconciled through accounting procedure, it was able to partition different components including water that was available through recharge. Soil water predicted by the RH model could not be compared with the TM approach as the TM method used observed soil water to compute change in storage calculation.

From the site-wise calculations, we computed the average hydrological response by taking average of P, PET, ET act, STOR and runoff as an approximation for the regional assessment of hydrology in the study area (Table 3). Fig. 6 also shows the average water balance components for AIN, ARA, GUD and ONE. The characteristics of the Sandhills hydrological processes were clearly seen from the regional values of monthly precipitation and the estimates of PET and $\mathrm{ET}_{\text {act }}$. The cumulative $\mathrm{ET}_{\text {act }}$ of $861 \mathrm{~mm}$ and PET of $1214 \mathrm{~mm}$ suggested a deficit of about 353 $\mathrm{mm}$ for a year. The monthly time-series representation of precipitation, PET and $\mathrm{ET}_{\text {act }}$ shown in Fig. 6 suggest that deficit existed between March and December. Despite PET and ET act being equal in magnitude between December and March, the soil water conditions and precipitation led to surplus. This could be evidenced with increasing lake levels and appearance of ephemeral open water bodies and water table levels in the region during the same time (Bleed and Flowerday, 1998; Gosselin et al., 2006). There were periods of soil water recharge between January and June, which are normally pre-growing and or the greening-up period. The soil water recharge occurred between September through December when plant senescence started and the growth activity gradually reduced. It also shows that precipitation was much lower than the demand and by April-May, the well-established root system started extracting soil water. We can also see from Fig. 6, a decline in the plant activity deduced from the decreased 
$\mathrm{ET}_{\text {act }}$ after July as the plants enter into senescence and soil water extraction also decreased. While most of the precipitation that fell through the crop growing period was fully utilized by the plants, it is possible that the annual demand for ET might only be met through additional supply of either ground or surface water storage. This could be in addition to soil water at the root zone level, particularly from the High Plains aquifer that exists beneath the Sandhills region and plays an important role in the hydrologic cycle of the Sandhills. In analyses of replicated 300 $\mathrm{cm}$ deep cores from upland Sandhills grasslands, $91 \%$ of root biomass and $96 \%$ of root length were found on average in the top $100 \mathrm{~cm}$. The top $150 \mathrm{~cm}$ contained $94 \%$ root mass and $98 \%$ of root length (Sridhar et al., 2006). Soil water profiles to $300 \mathrm{~cm}$ depth, also supported the conclusion that minimal soil water uptake occurred for the dominant grasses beneath $150 \mathrm{~cm}$. But, the regional ground water table had a general rise in the Fall and Spring season and it subsequently depleted in the growing season due to root water uptake before being recharged again. This result is also supported by the recent findings of Gosselin et al. (2006) where strong correlation between ET and ground water is reported. This interesting root water uptake phenomenon is also another testimony to this factor, as the dune-top grass roots extend down below to deeper depths in search of water and the water-rich interdunal valley that supports the short grass has a relatively shallow root system. Thus, the enormity of the dynamics of subsurface-surface interaction in the Sandhills can not be understated. The plant ecosystem of the Sandhills and highly permeable sand dunes are in a delicate balance supported by the sub-surface ground water system.

\section{Conclusion}

This study employed the TM water balance model to evaluate the water balance components for the Sandhills region. We have demonstrated that simple models can be an alternative to study the hydroclimatology of a homogeneous terrain. Estimates of the water balance components for various sites showed that the method is useful in understanding the plant-soil-groundwater dynamics at a monthly timescale. Average precipitation of the region is about $420 \mathrm{~mm}$. AIN received the highest amount of $465 \mathrm{~mm}$ per year while ARA and GUD received the lowest of about $370 \mathrm{~mm}$. Average PET of this grasslands region was about $1214 \mathrm{~mm}$ and all of the sites had PET of over 1000 $\mathrm{mm}$ per year. The soil water storage demonstrated significant variability among these sites. High precipitation and silty soil at AIN resulted in a high soil water storage value of $244 \mathrm{~mm} / \mathrm{month}$ and ARA had the lowest soil water storage of $100 \mathrm{~mm} / \mathrm{month}$. GUD and ONE had soil water storage of 166 and $120 \mathrm{~mm} / \mathrm{month}$. Clearly, there was a seasonal variation in soil water storage with its peak value in April-May and decreasing storage once the ET process began in May-June. $\mathrm{ET}_{\text {act }}$ of the grasslands were about $861 \mathrm{~mm}$ and indicated the water-controlled ecosystem of the Sandhills is particularly influenced by the local hydrology and it can be seen from the range in $\mathrm{ET}_{\text {act }}$ of 700-1000 $\mathrm{mm} /$ year. The surplus during the winter months and deficit during the remaining time of the year showed strong exchange phenomenon between surface and ground water systems. Average runoff from this grasslands region was about $247 \mathrm{~mm}$. This preliminary study therefore suggests that there is a growing need to understand this complex surface-ground water interaction and refine the estimates of the water balance components. 


\section{References}

Bleed, A.S., \& Flowerday, C.A. (1998) Introduction. In: Bleed, A.S., and Flowerday, C.A.(Editors.), An Atlas of the Sandhills. Conservation and Survey Division, IANR, University of Nebraska-Lincoln, Resource Atlas No. 5a, 1-15.

Chen, X., \& Chen, X. (2004) Simulating the effects of reduced precipitation on ground water and streamflow in the Nebraska Sandhills. J. Amer. Water Resour. Assoc. 40(2), 419-430.

Delworth, T., \& Manabe, S. (1988) The influence of potential evaporation on the variability of simulated soil wetness and climate. J. Clim., 1, 523-547.

Delworth, T., \& Manabe, S. (1989) The influence of soil wetness on near-surface atmospheric variability. J. Clim., 2, $1447-1462$.

Feddema, J. (1998) Estimated impacts of soil degradation on the African water balance and climate. Clim. Research, $10,127-141$

Gosselin, D.C., Drda, S., Harvey, F.E., \& Goeke, J. (1999) Hydrologic dynamics of two interdunal valleys in the Central Sandhills Nebraska. Ground Water, 37, 924-933.

Gosselin, D.C., Sridhar, V., Harvey, F.E., \& Goeke, J. (2006) Hydrological effects and groundwater fluctuations in interdunal environments in the Nebraska Sandhills. Great Plains Research, (accepted)

Hebert, M. T., \& Jack, S.B. (1998) Leaf area index and site water balance of loblolly pine (Pinus taeda L.) across a precipitation gradient in east Texas. Forest Ecology and Management, 105 (1-3), 273-282.

Hubbard, K. G., Rosenberg, N. J. and Nielsen, D. J. (1983). An automated weather data network in support of agricultural operations. J. Water Resources Planning and Management 109:213-22.

Iturbe, R.I. (2000) Ecohydrology: A hydrologic perspective of climate-soil-vegetation dynamics. Water Resour. Res., Vol. 36, No. 1, 3-9.

Loope, D.B., \& Swinehart, J.B. (2000) Thinking like a dune field. Great Plains Res., 10: 5-35.

Mahmood, R., \& Hubbard, K.G. (2003) Simulating sensitivity of soil moisture and evapotranspiration under heterogeneous soils and land uses. J. Hydrol., 280, 72-90.

McPherson, R.A., Fiebrich, C.A., Crawford, K.C. Elliott, R.L., Kilby, J.R. Grimsley, D.L., Martinez, J.E. Basara, J.B., Illiston, B.G., Morris, D.A., Kloesel, K.A., Stadler, S. J., Melvin, A.D.,Sutherland, A.J., Shrivastava, H., Carlson, J.D., Wolfinbarger, J.M., Bostic, J.P., Demko, D.B., (2007) Statewide monitoring of the mesoscale environment: a technical update on the Oklahoma Mesonet. J Atmospheric and Oceanic Technology, 24(3) 301321.

Singh, R.K., Hari Prasad, V., \& Bhatt, C.M. (2004) Remote sensing and GIS approach for assessment of the water balance of a watershed. Hydrol. Sci. J. 49(1), 131-141.

Sridhar, V., Elliott, R.L., Chen, F., \& Brotzge, J.A. (2002) Validation of the NOAH-OSU Land Surface Model using surface flux measurements in Oklahoma. J. Geophys. Res.,Vol. 107, No. D20, 4418, doi: 10.1029/2001JD001306.

Sridhar, V., Hubbard, K.G., \& Wedin,D.A. (2006). Assessment of soil moisture dynamics of the Nebraska Sandhills using Long-Term measurements and a hydrology model, ASCE Journal of Irrigation and Drainage Engg. Vol. 132, Issue 5, pp 463-473, 10.1061/(ASCE)0733-9437(2006)132:5(463). 


\section{List of Tables}

Table 1. Monthly calculation of water balance using the TM model for four sites in the Sandhills (values are in mm); P-Precipitation; PET-Potential Evapotranspiration; STOR-storage;D-STOR-change in storage; AET-Actual Evapotranspiration; DEF-Deficit; SUR-Surplus; Avail. RO-Available Runoff.

Table 2. Statistical analysis showing the Robinson-Hubbard hydrology model's root zone soil water prediction performance for the study sites where units on RMSE are in mm.(Sridhar et al., 2006)

Table 3. Estimated water balance components for the Sandhills based on the averages of seasonal PET, ET act, $_{\text {STOR }}$ and runoff (values are in $\mathrm{mm}$ ).

\section{List of Figures}

Fig. 1. Location map showing four AWDN sites and the Sandhills region.

Fig. 2. Topography and Vegetation maps of the Sandhills region.

Fig. 3. Average observed root zone soil water from AIN, ARA, GUD and ONE for the period of 1999 through 2003. Fig. 4. Estimated Annual Hydrologic Budget using Robinson-Hubbard Model (Sridhar et al., 2006) for four sites, AIN, ARA, GUD and ONE during 1999-2003. Drainage term given by the model provides the vertical flux of water beyond the root zone depth which can be related to the runoff term in this study that includes both surface runoff and surface drainage.

Fig. 5. Hydroclimatology and water balance partitioning of total precipitation, ET, drainage and average RobinsonHubbard hydrology model predicted and observed root zone soil water for AIN, ARA, GUD and ONE during 19982003 (Sridhar et al., 2006).

Fig. 6. Seasonal water balance estimates using the TM model that exhibit the dynamic interplay of precipitation, ET and soil water. 
This is an author-produced, peer-reviewed version of this article. The final, definitive version of this document can be found online at Journal of Hydrologic Engineering, published by American Society of Civil Engineers. Copyright restrictions may apply. DOI: 10.1061/(asce)he.1943-5584.0000157

\begin{tabular}{|c|c|c|c|c|c|c|c|c|c|c|c|c|c|}
\hline Site:AIN & Jan & Feb & Mar & Apr & May & Jun & |Jul & Aug & Sep & Oct & Nov & Dec & Total \\
\hline$P$ (tot) & 6 & 9 & 15 & 83 & 93 & 71 & 64 & 42 & 42 & 25 & 13 & 1 & 465 \\
\hline PET & 51 & 64 & 88 & 125 & 171 & 191 & 213 & 193 & 148 & 112 & 75 & 43 & 1476 \\
\hline P-PET & -45 & -55 & -73 & -42 & -78 & -120 & -149 & -151 & -106 & -88 & -62 & -42 & \\
\hline STOR & 226 & 232 & 262 & 309 & 347 & 300 & 248 & 224 & 204 & 191 & 192 & 203 & 2939 \\
\hline D-STOR & 23 & 6 & 30 & 47 & 38 & -47 & -52 & -24 & -20 & -12 & 1 & 12 & \\
\hline AET & 51 & 64 & 88 & 125 & 171 & 118 & 116 & 67 & 62 & 37 & 75 & 43 & 1018 \\
\hline DEF & 0 & 0 & 0 & 0 & 0 & 73 & 97 & 127 & 86 & 75 & 0 & 0 & 458 \\
\hline SUR & 0 & 0 & 102 & 89 & 116 & 0 & 0 & 0 & 0 & 0 & 0 & 0 & 308 \\
\hline Avai.RO & 0 & 0 & 102 & 140 & 187 & 93 & 47 & 23 & 12 & 6 & 3 & 1 & 614 \\
\hline Runoff & 0 & 0 & 51 & 70 & 93 & 47 & 23 & 12 & 6 & 3 & 1 & 1 & 307 \\
\hline Detention & 0 & 0 & 51 & 70 & 93 & 47 & 23 & 12 & 6 & 3 & 1 & 1 & 307 \\
\hline & & & & & & & & & & & & & \\
\hline Site:ARA & Jan & Feb & Mar & Apr & May & Jun & Jul & Aug & Sep & Oct & Nov & Dec & Total \\
\hline$P$ (tot) & 4 & 2 & 16 & 49 & 58 & 48 & 70 & 40 & 52 & 27 & 7 & 0 & 373 \\
\hline PET & 34 & 40 & 66 & 103 & 138 & 179 & 197 & 176 & 121 & 71 & 38 & 27 & 1191 \\
\hline P-PET & -30 & -38 & -50 & -53 & -80 & -131 & -128 & -136 & -69 & -45 & -30 & -27 & \\
\hline STOR & 119 & 134 & 142 & 136 & 61 & 61 & 80 & 102 & 98 & 100 & 97 & 74 & 1205 \\
\hline D-STOR & 46 & 14 & 9 & -6 & -75 & -1 & 19 & 22 & -4 & 1 & -3 & -23 & \\
\hline $\mathrm{AET}$ & 34 & 40 & 66 & 56 & 133 & 49 & 197 & 176 & 55 & 71 & 10 & 23 & 911 \\
\hline DEF & 0 & 0 & 0 & 47 & 5 & 130 & 0 & 0 & 66 & 0 & 27 & 4 & 280 \\
\hline SUR & 76 & 53 & 58 & 0 & 0 & 0 & 0 & 158 & 0 & 0 & 0 & 0 & 345 \\
\hline Avai.RO & 76 & 90 & 104 & 52 & 26 & 13 & 6 & 162 & 81 & 40 & 20 & 10 & 680 \\
\hline Runoff & 38 & 45 & 52 & 26 & 13 & 6 & 3 & 81 & 40 & 20 & 10 & 5 & 340 \\
\hline Detention & 38 & 45 & 52 & 26 & 13 & 6 & 3 & 81 & 40 & 20 & 10 & 5 & 340 \\
\hline & & & & & & & & & & & & & \\
\hline Site:GUD & Jan & Feb & Mar & Apr & May & Jun & Jul & Aug & Sep & Oct & Nov & Dec & Total \\
\hline$P$ (tot) & 5 & 5 & 17 & 58 & 60 & 49 & 73 & 27 & 42 & 21 & 12 & 3 & 370 \\
\hline PET & 33 & 37 & 63 & 96 & 132 & 162 & 181 & 168 & 116 & 70 & 38 & 24 & 1119 \\
\hline P-PET & -28 & -32 & -46 & -38 & -72 & -113 & -109 & -141 & -74 & -49 & -26 & -21 & \\
\hline STOR & 164 & 174 & 230 & 254 & 252 & 207 & 125 & 99 & 115 & 106 & 126 & 137 & 1990 \\
\hline D-STOR & -27 & 10 & 57 & 23 & -2 & -44 & -82 & -27 & 16 & -9 & 19 & 12 & \\
\hline AET & 32 & 37 & 63 & 96 & 62 & 93 & 155 & 53 & 116 & 30 & 38 & 24 & 798 \\
\hline DEF & 1 & 0 & 0 & 0 & 70 & 69 & 27 & 114 & 0 & 40 & 0 & 0 & 321 \\
\hline SUR & 0 & 41 & 102 & 61 & 0 & 0 & 0 & 0 & 0 & 0 & 0 & 0 & 205 \\
\hline Avai.RO & 0 & 41 & 123 & 123 & 62 & 31 & 15 & 8 & 4 & 2 & 1 & 0 & 410 \\
\hline Runoff & 0 & 21 & 62 & 62 & 31 & 15 & 8 & 4 & 2 & 1 & 0 & 0 & 205 \\
\hline Detention & 0 & 21 & 62 & 62 & 31 & 15 & 8 & 4 & 2 & 1 & 0 & 0 & 205 \\
\hline & & & & & & & & & & & & & \\
\hline & & & & & & & & & & & & & \\
\hline Site:ONE & Jan & Feb & Mar & Apr & May & Jun & Jul & Aug & Sep & Oct & Nov & Dec & Total \\
\hline$P$ (tot) & 7 & 10 & 15 & 74 & 86 & 68 & 61 & 42 & 40 & 42 & 23 & 1 & 470 \\
\hline PET & 28 & 34 & 58 & 92 & 127 & 158 & 175 & 154 & 119 & 68 & 36 & 23 & 1072 \\
\hline P-PET & -21 & -24 & -42 & -18 & -40 & -90 & -114 & -111 & -79 & -26 & -13 & -22 & \\
\hline STOR & 109 & 111 & 132 & 143 & 146 & 124 & 121 & 111 & 107 & 108 & 112 & 113 & 1437 \\
\hline D-STOR & 4 & 3 & 21 & 11 & 4 & -23 & -3 & -10 & -4 & 1 & 4 & 1 & \\
\hline AET & 28 & 34 & 58 & 92 & 127 & 91 & 64 & 52 & 43 & 68 & 36 & 23 & 716 \\
\hline DEF & 0 & 0 & 0 & 0 & 0 & 67 & 111 & 102 & 75 & 0 & 0 & 0 & 355 \\
\hline SUR & 0 & 0 & 63 & 29 & 44 & 0 & 0 & 0 & 0 & 0 & 0 & 0 & 136 \\
\hline Avai.RO & 0 & 0 & 63 & 61 & 74 & 37 & 19 & 9 & 5 & 2 & 1 & 1 & 271 \\
\hline Runoff & 0 & 0 & 32 & 30 & 37 & 19 & 9 & 5 & 2 & 1 & 1 & 0 & 136 \\
\hline Detention & 0 & 0 & 32 & 30 & 37 & 19 & 9 & 5 & 2 & 1 & 1 & 0 & 136 \\
\hline
\end{tabular}

Table 1 
This is an author-produced, peer-reviewed version of this article. The final, definitive version of this document can be found online at Journal of Hydrologic Engineering, published by American Society of Civil Engineers. Copyright restrictions may apply. DOI: 10.1061/(asce)he.1943-5584.0000157

\begin{tabular}{|c|c|c|c|c|c|c|c|c|c|c|c|c|}
\hline \multirow[t]{2}{*}{ Site } & \multicolumn{2}{|c|}{ 1998-99 } & \multicolumn{2}{|c|}{ 1999-00 } & \multicolumn{2}{|c|}{$2000-01$} & \multicolumn{2}{|c|}{$2001-02$} & \multicolumn{2}{|c|}{$2002-03$} & \multicolumn{2}{|c|}{ 2003-04 } \\
\hline & RMSE & $r$ & RMSE & $\mathrm{r}$ & RMSE & $r$ & RMSE & $r$ & RMSE & $r$ & RMSE & r \\
\hline AIN & 95.97 & 0.50 & 30.33 & 0.97 & 49.91 & 0.04 & 19.13 & 0.88 & 52.01 & 0.90 & 37.59 & 0.93 \\
\hline ARA & 35.17 & 0.84 & 52.06 & 0.72 & 46.48 & 0.58 & 41.33 & -0.07 & 14.95 & 0.75 & 15.86 & 0.86 \\
\hline GUD & 46.60 & 0.94 & 51.95 & 0.81 & 35.45 & 0.63 & 48.63 & 0.93 & 27.29 & 0.87 & 23.25 & 0.87 \\
\hline ONE & 22.20 & 0.80 & 20.73 & 0.82 & 36.78 & 0.44 & 27.51 & 0.53 & 17.77 & 0.55 & 16.26 & 0.83 \\
\hline
\end{tabular}

Table 2

The Pearson product moment correlation coefficient, r, is:

$$
y=\frac{\sum(x-\bar{x})(y-\bar{y})}{\sqrt{\sum(x-x)^{2} \sum(y-y)^{2}}}
$$

where $x$ and $y$ are observed and modeled soil water, $\bar{x}$ and $\bar{y}$ are the observed and modeled soil water sample means.

$R M S E=\sqrt{\frac{\left[\sum_{i=1}^{n}(P-O)^{2}\right]}{n}}$

where $P$ is the predicted value, $O$ is the observed value and $n$ is the sample size.

\begin{tabular}{|l|r|r|r|r|r|r|r|r|r|r|r|r|r|}
\hline & Jan & Feb & Mar & Apr & May & Jun & Jul & Aug & Sep & Oct & Nov & Dec & Total \\
\hline P(tot) & 6 & 7 & 16 & 66 & 74 & 59 & 67 & 38 & 44 & 29 & 14 & 1 & 420 \\
\hline PET & 37 & 44 & 69 & 104 & 142 & 173 & 192 & 173 & 126 & 80 & 47 & 29 & 1214 \\
\hline ETact & 36 & 44 & 69 & 92 & 123 & 88 & 133 & 87 & 69 & 52 & 40 & 29 & 861 \\
\hline ST0R & 155 & 163 & 192 & 210 & 202 & 173 & 144 & 134 & 131 & 126 & 132 & 132 & 1893 \\
\hline Runoff & 9 & 16 & 49 & 47 & 44 & 22 & 11 & 25 & 13 & 6 & 3 & 2 & 247 \\
\hline
\end{tabular}

Table 3 
This is an author-produced, peer-reviewed version of this article. The final, definitive version of this document can be found online at Journal of Hydrologic Engineering, published by American Society of Civil Engineers. Copyright restrictions may apply. DOI: 10.1061/(asce)he.1943-5584.0000157

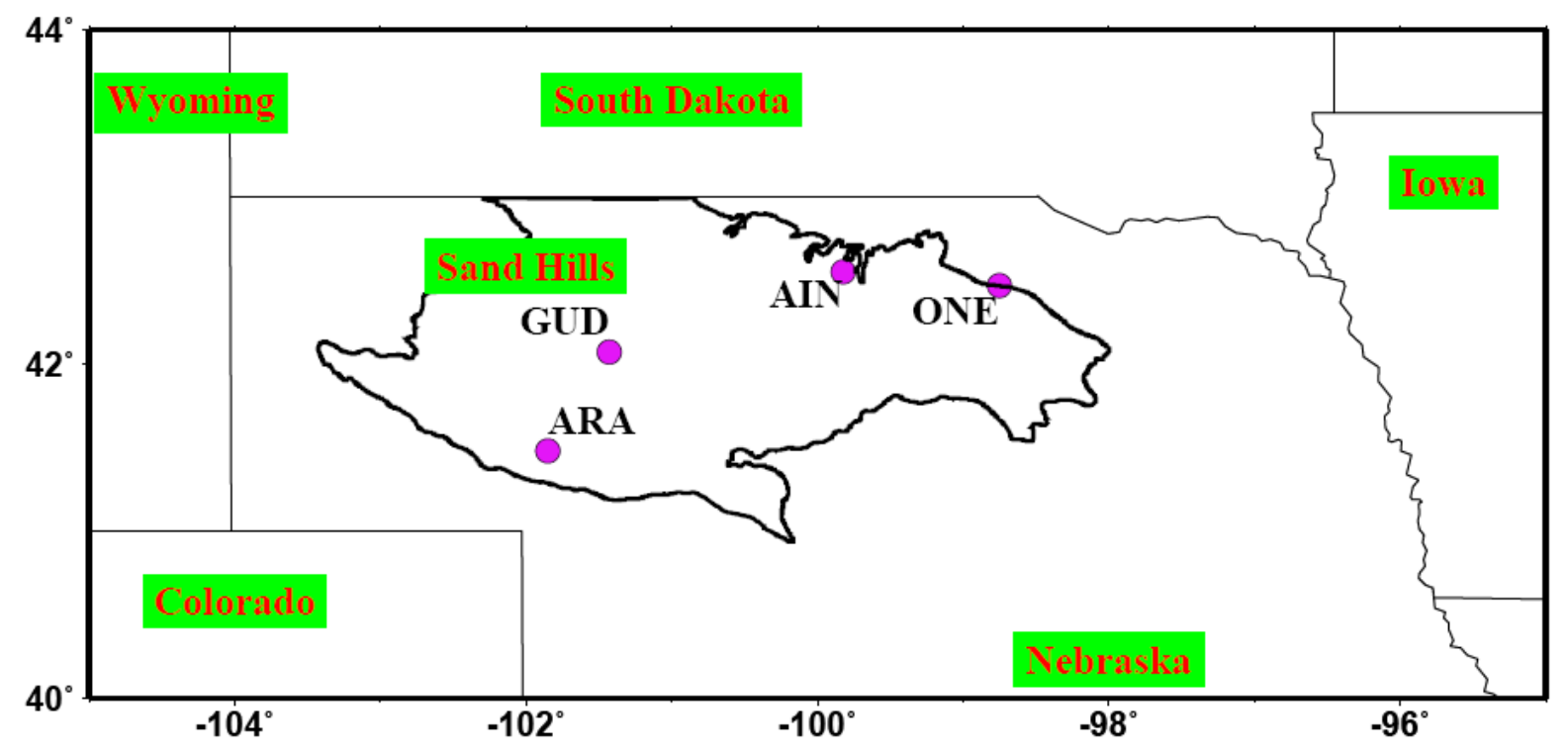

Fig. 1 
This is an author-produced, peer-reviewed version of this article. The final, definitive version of this document can be found online at Journal of Hydrologic Engineering, published by American Society of Civil Engineers. Copyright restrictions may apply. DOI: 10.1061/(asce)he.1943-5584.0000157
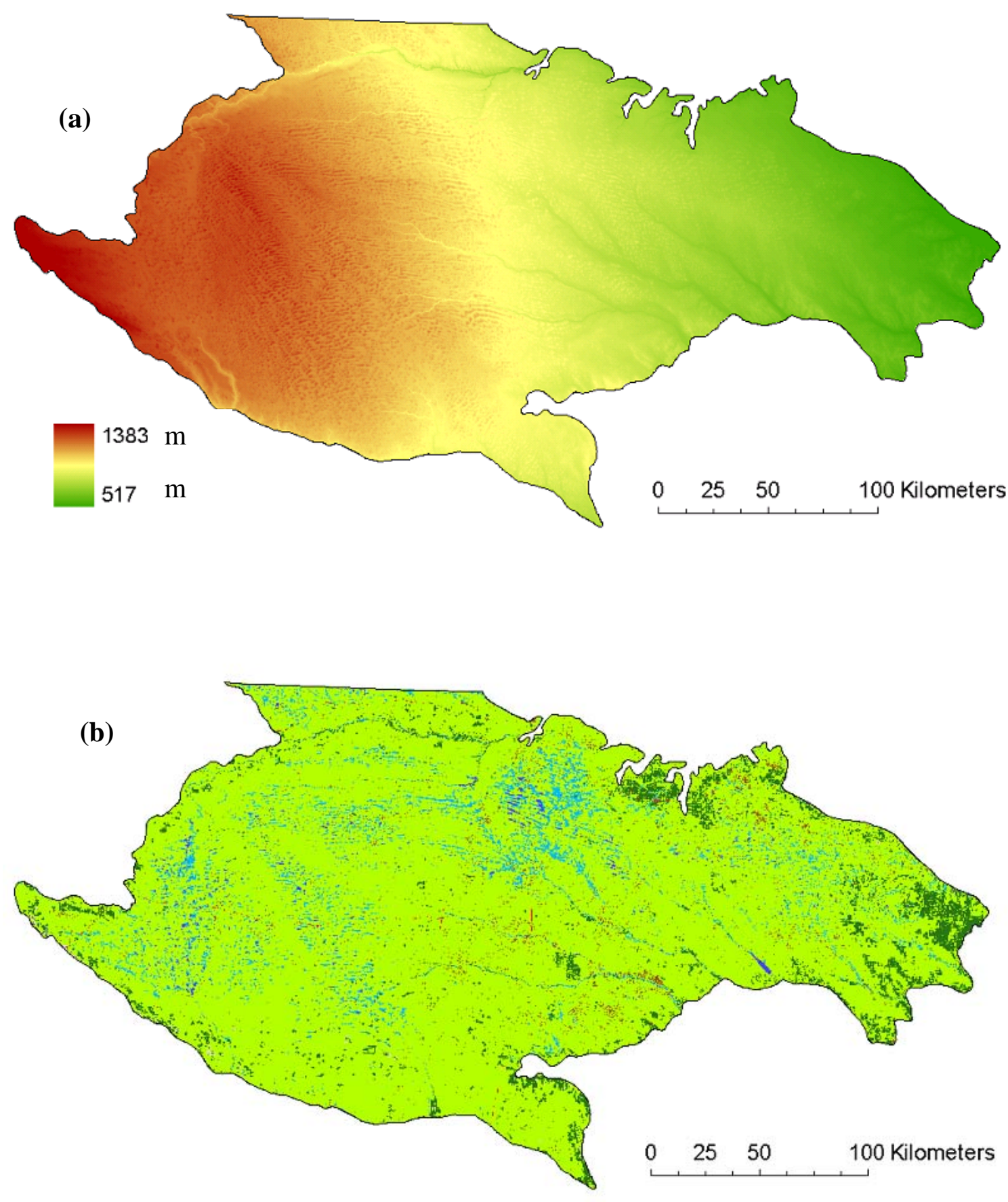

No Data
Agriculture
$\square$ Range, Pasture, Grass
Urban Land
Open Water

Wetlands

Summer Fallow

Roads

Fig. 2

Barren 
This is an author-produced, peer-reviewed version of this article. The final, definitive version of this document can be found online at Journal of Hydrologic Engineering, published by American Society of Civil Engineers. Copyright restrictions may apply. DOI: 10.1061/(asce)he.1943-5584.0000157

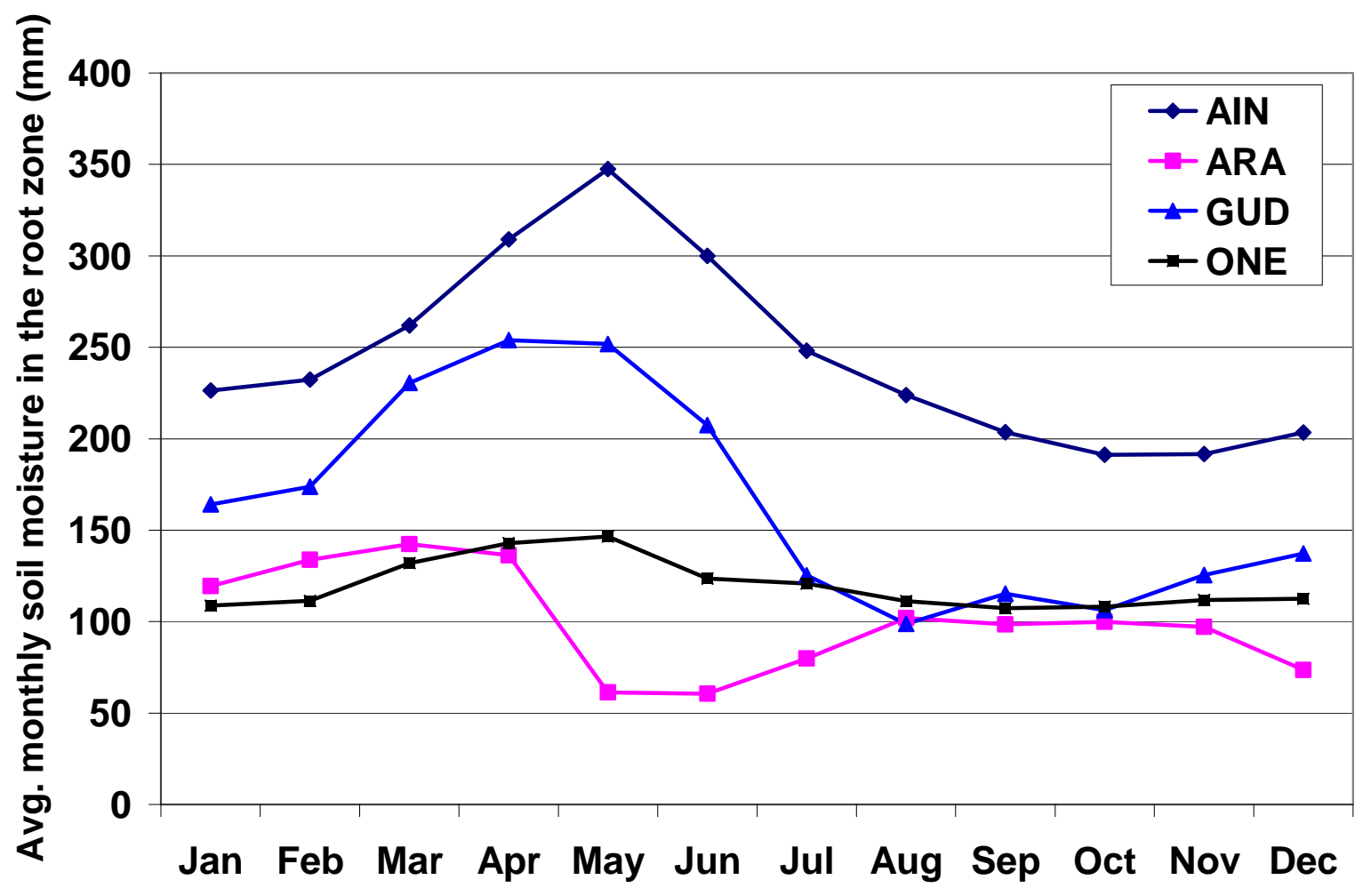

Fig 3 

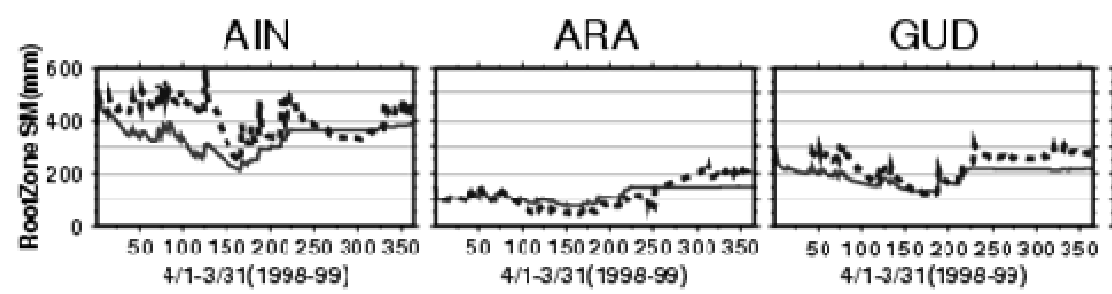

ONE
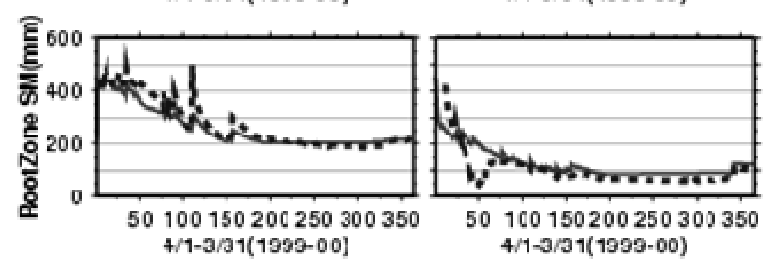

4/1-3/31(1998-99)
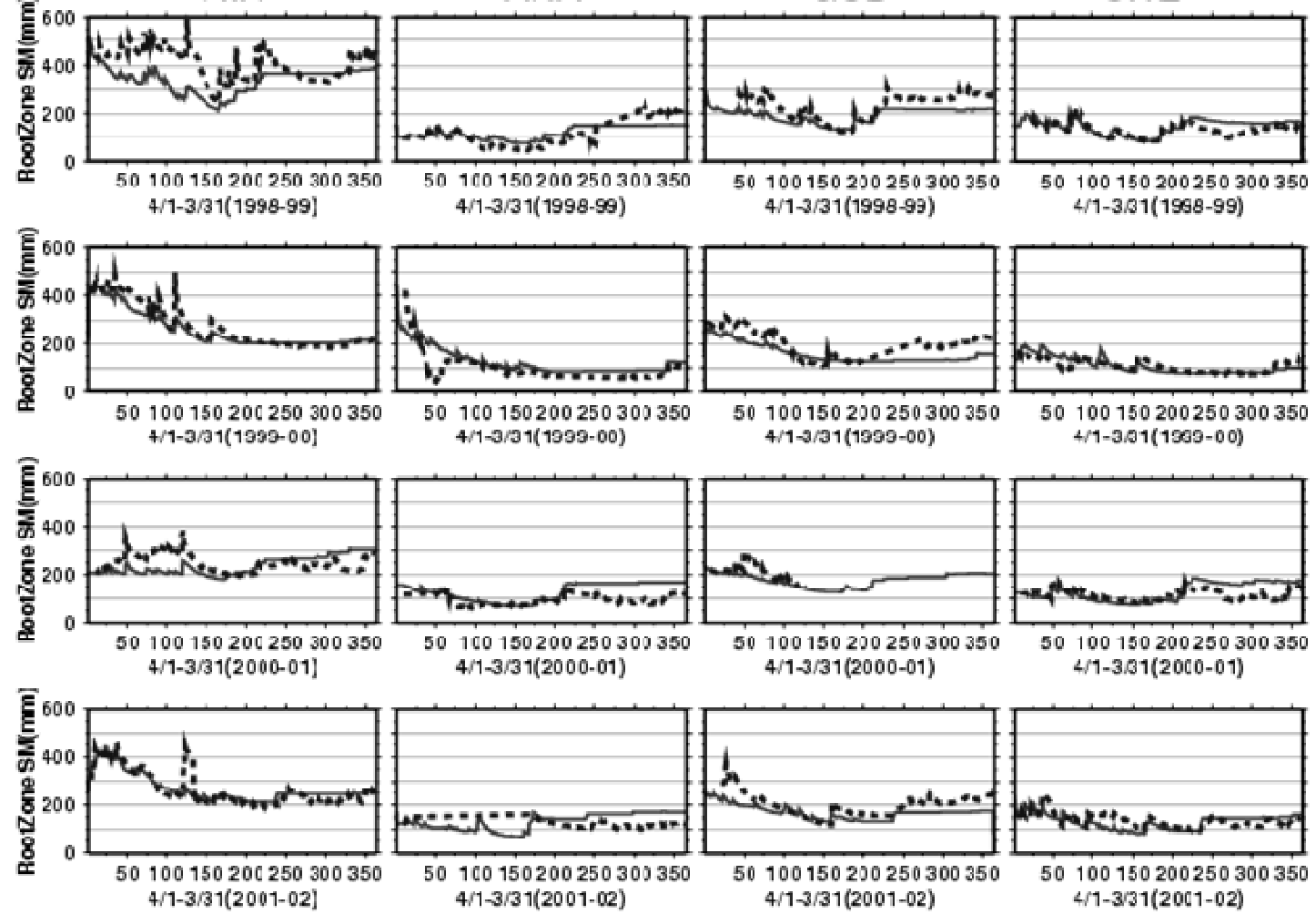
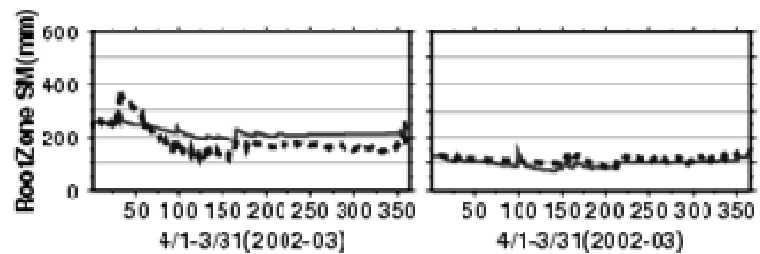

$4 / 1-3 / 31(2001-02)$

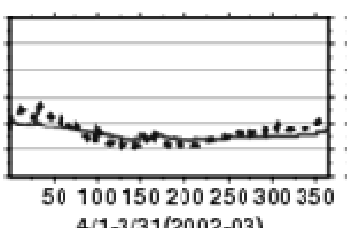

$4 / 1-3 / 31(2002-03)$
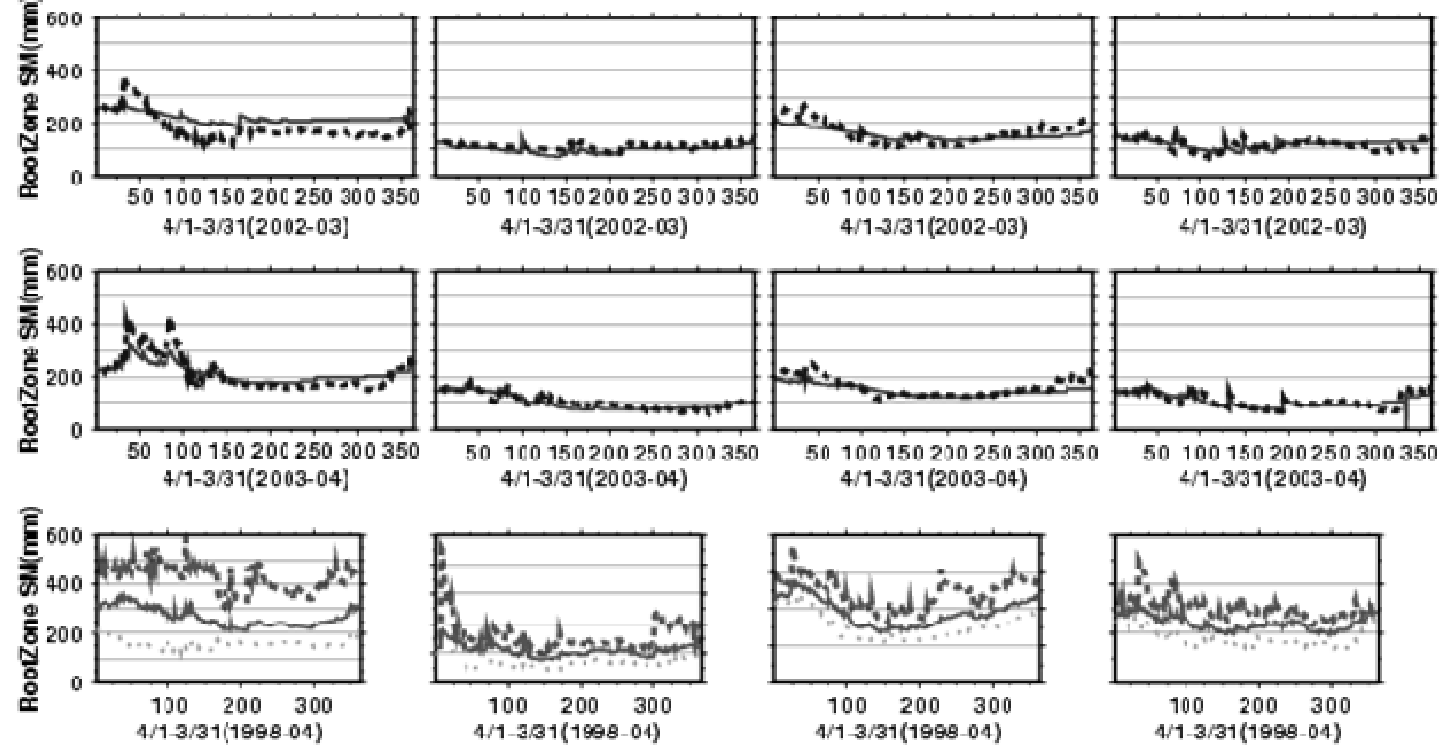

-....-.
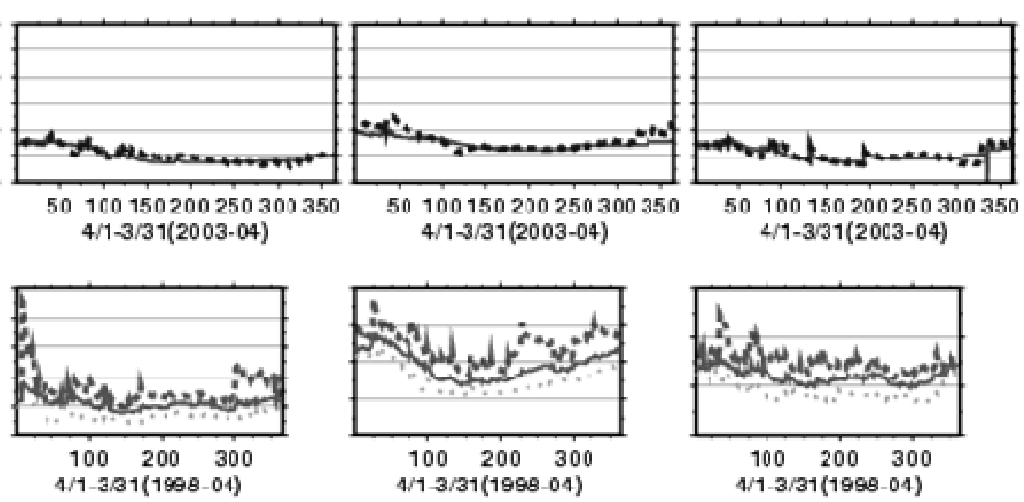

$100 \quad 200 \quad 300$

Historic Max.(1998-2004)

-3/31(1968-04)

Historic Min.(1998-2004) …... Obs.SM

Historic Mean (1998-2004)

Fig 4 
This is an author-produced, peer-reviewed version of this article. The final, definitive version of this document can be found online at Journal of Hydrologic Engineering, published by American Society of Civil Engineers. Copyright restrictions may apply. DOI: 10.1061/(asce)he.1943-5584.0000157
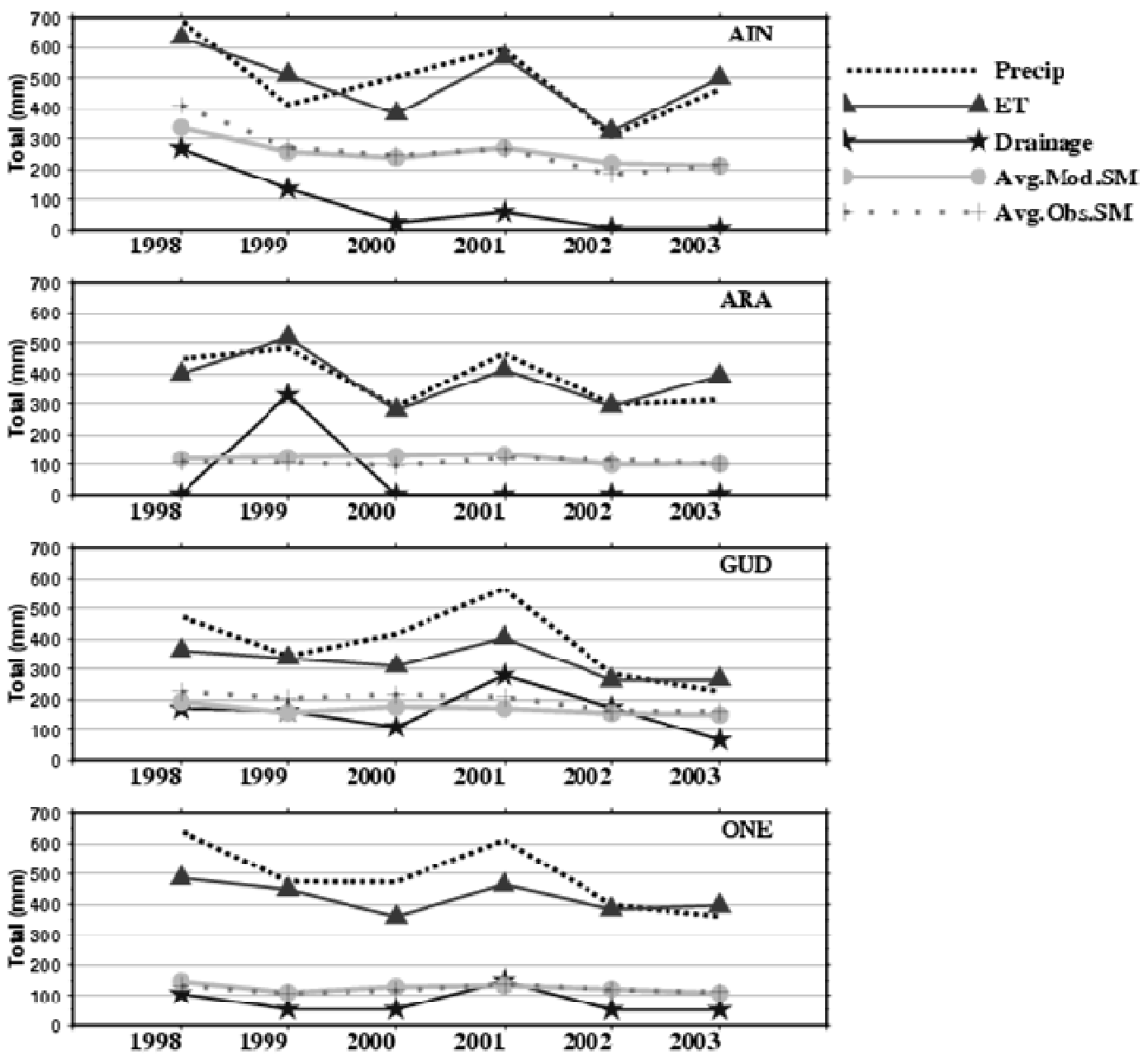

Fig 5 
This is an author-produced, peer-reviewed version of this article. The final, definitive version of this document can be found online at Journal of Hydrologic Engineering, published by American Society of Civil Engineers. Copyright restrictions may apply. DOI: 10.1061/(asce)he.1943-5584.0000157

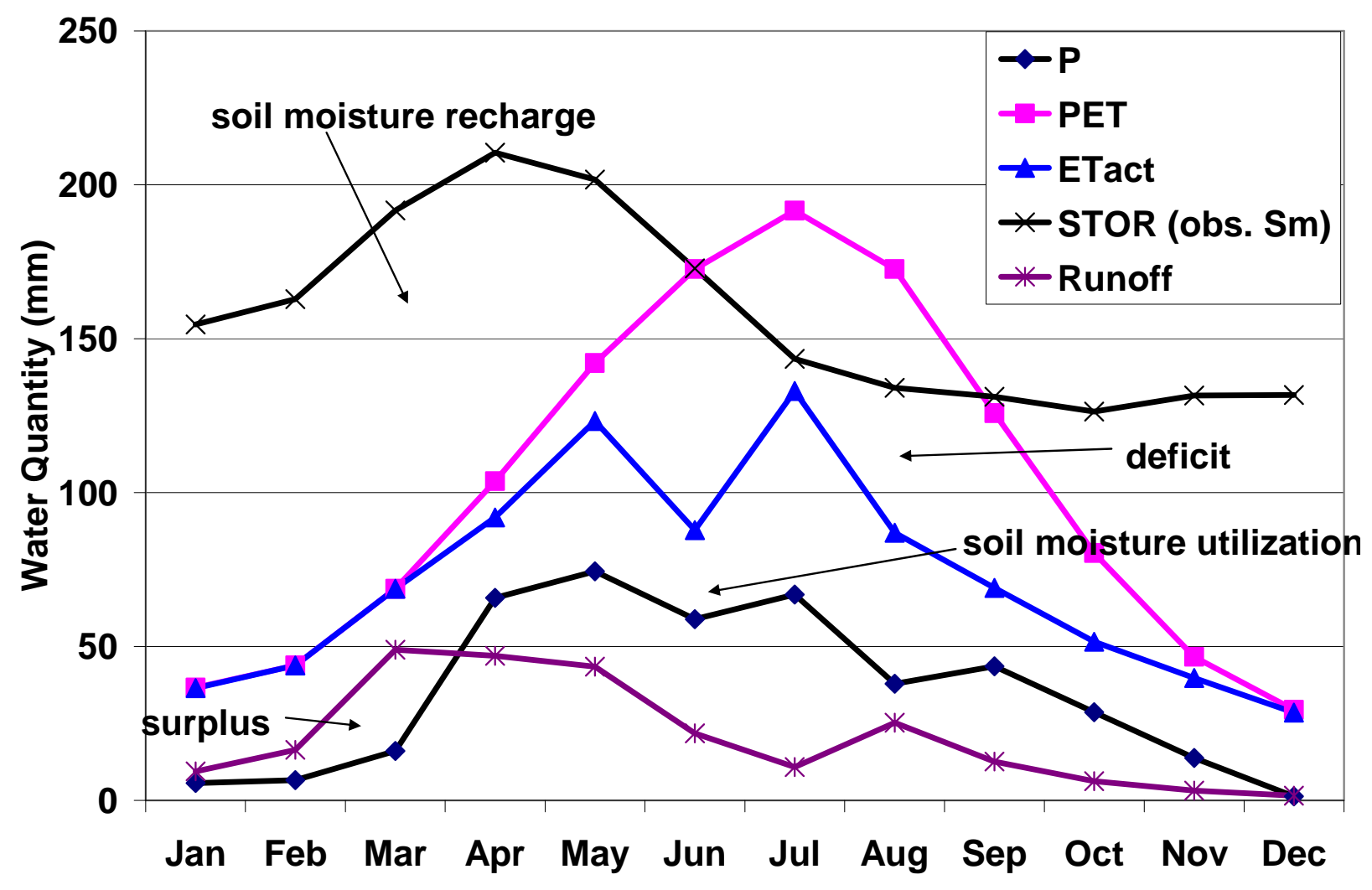

Fig. 6 